\title{
TEATRO E MUDANÇA ORGANIZACIONAL
}

\section{RESUMO}

Teatro organizacional significa, antes de mais nada, peças customizadas encenadas para uma determinada organização ou subgrupo em uma organização. A peça normalmente dramatiza uma situação-problema crítica da organização em questão. Situações problemáticas típicas, dramatizadas em peças do teatro organizacional, podem ser conflitos entre duas culturas corporativas após uma fusão ou barreiras de comunicação entre a média e a baixa gerência. É grande a variação dos estilos utilizados no teatro organizacional: realista, naturalista, melodramático, absurdo, burlesco, etc. Independentemente do estilo, o teatro organizacional expõe a platéia a situações de sua rotina de trabalho e a confronta com conflitos ocultos, padrões inconscientes de comportamento ou rotinas críticas. A tese deste trabalho é de que o teatro organizacional pode ser um meio poderoso em processos de mudança organizacional. Ele pode liberar conflitos paralisados ou abrir para discussão o que não se discute. O teatro organizacional pode fazer as coisas se moverem. No entanto, ele não é um substituto ao gerenciamento de mudanças. Se a organização não faz idéia de como lidar com a irritação teatral ou de como transformar a energia evocada em mudança organizacional, a performance teatral pode tornar-se uma intervenção isolada, sem nenhum efeito duradouro. Por esse motivo, atividades adequadas de acompanhamento são postuladas como imperativas.

\section{Georg Schreyögg}

Professor-Doutor da Universidade Livre de Berlim.

E-mail: schrey@wiwiss.fu-berlin.de

\begin{abstract}
Organizational theatre means first of all tailor-made plays staged for a specific organization or a subgroup in an organization. The play usually dramatizes a critical problem situation faced by the organization in question. Typical problem situations dramatized in organizational theatre plays are: conflicts between two corporate cultures after a merger or communication barriers between middle and lower management. The range of realization styles that are used in organizational theatre is broad: realistic, naturalistic, melodramatic, absurd, burlesque etc. Whatever the style organizational theatre exposes the audience to situations of their daily working life, thereby confronting it with hidden conflicts, subconscious behavioral patterns or critical routines. It is the thesis of this paper that organizational theatre can be a powerful medium in organizational change processes. It can open conflicts that are deadlocked or can render undiscussibles discussible. Organizational theatre can make things move. However, it is not a substitute for change management. If the organization has no idea how to work on the theatrical irritation, how to transform the evoked energy into organizational change, the theatre performance is likely to become a single intervention without any lasting effects. Adequate follow up activities are therefore postulated as imperative.
\end{abstract}

PALAVRAS-CHAVE Teatro, organizações, mudança organizacional, teatro organizacional, performance.

KEY WORDS Theatre, organizations, organizational change, organizational theatre, performance. 


\section{INTRODUÇÃO}

As intervenções teatrais em organizações não são tão recentes como pode parecer. Mesmo no mundo antigo havia a tradição de utilizar o teatro para expressar preocupações, revelar conflitos, refletir planos e/ou iniciar discussões em determinados assuntos. O teatro era um elemento natural da vida política e do discurso público na Polis Grega, representando um fórum para a formação de opiniões e para manter os assuntos abertos a mudanças.

De forma similar, organizações na França, no Canadá, na Alemanha e em alguns outros países começaram recentemente a utilizar o teatro como um instrumento. Grupos teatrais encenam peças customizadas para organizações específicas, dramatizando problemas críticos na rotina de trabalho. Tais encenações não são raras. Em 1997, por exemplo, foram promovidas duas mil encenações teatrais em organizações francesas e 200 nas alemãs (Wehner e Dabitz, 1999).

De forma geral, nota-se um interesse surpreendentemente grande e crescente em trabalhar com esse instrumento incomum. Atualmente, muitas organizações - em particular, corporações na França e na Alemanha - estão considerando o trabalho com o teatro organizacional. Como no mundo antigo, na maioria dos casos o teatro organizacional é utilizado como um meio de comunicação no contexto de conflitos e mudanças.

Entretanto, o que exatamente significa teatro organizacional? Por que as organizações estão interessadas em utilizá-lo? Quais são os resultados possíveis das intervenções teatrais em processos de mudança organizacional?

Este artigo visa a fornecer respostas a essas questões. O conhecimento teórico tem raízes na teoria dos sistemas sociais.

\section{O CONCEITO DO TEATRO ORGANIZACIONAL}

Quase todas as organizações ocasionalmente encontram formas de trabalho teatral (Petzold, 1972; Rosen, 1988; Schreyögg, 1999), bem conhecidas como role plays (encenações de papéis), em workshops de desenvolvimento gerencial, cabarés de funcionários em festas de natal, peças teatrais corporativas amadoras, apresentações teatrais de novos produtos - em feiras ou lojas de departamento -, eventos espetaculares em reuniões anuais, etc. Todas essas formas de trabalho teatral são muito instigantes e dignas de atenção. No entanto, teatro organizacional, do modo como a noção é aqui utilizada, significa algo diferente.

Teatro organizacional na tradição francesa (Poissonneau, 1992; Leplâtre, 1996; Aragou-Dournon, 1999) significa, antes de mais nada, peças customizadas encenadas para uma determinada organização ou subgrupo em uma organização. Basicamente, o conceito de teatro organizacional (Beckerman, 1990) é definido por quatro elementos:

1. Apresentação teatral: Atores profissionais encenam uma peça. Em outras palavras, há um palco, atores, uma platéia, um dramaturgo, etc. Há um teatro no sentido clássico da palavra.

2. Especificidade organizacional: A peça é customizada, dramatizando uma situação-problema especificamente enfrentada pela organização em questão. O enredo e o roteiro são definidos após uma exploração do problema específico e de seu contexto organizacional.

3. Público definido: A atuação é endereçada a uma platéia claramente definida - como, por exemplo, um determinado departamento, uma fábrica, o pessoal de vendas, os gerentes de uma filial. A platéia também pode provir de diferentes organizações - como no caso de joint ventures ou redes de empresas.

4. Encomenda: Normalmente, o teatro organizacional é um teatro encomendado. A organização-cliente encomenda a peça de teatro e paga pela produção.

As situações problemáticas típicas, dramatizadas até o momento, em peças de teatro organizacional são: conflitos entre duas culturas corporativas no contexto de uma integração pós-fusão, barreiras de comunicação entre a média e a baixa gerência, desencorajamento de novas idéias, "pensamento em grupo" em reuniões de gerência, resistência a mudanças estratégicas, micropolítica em processos de investimento, etc. (para mais exemplos, ver Schreyögg e Dabitz, 1999).

\section{PROCESSO DE PRODUÇÃO}

Para entendermos a lógica do teatro organizacional e suas implicações para a mudança organizacional, é necessário considerar não somente a atuação, mas também o processo de produção como um todo. Para estudar tal processo, pode ser útil conceber o grupo teatral como uma organização de serviços, envolvendo uma cadeia de atividades que visa à criação de valor distintivo. Desse ponto de vista, um processo 
típico de produção envolveria um conjunto distinto de atividades e etapas, conforme mostrado na Figura 1.

As várias etapas do processo podem ser caracterizadas como se segue:

- Encomenda: A organização-cliente entra em contato com um ou mais grupos de teatro organizacional e esboça a situação-problema em questão. O grupo teatral verifica a viabilidade do projeto e negocia o contrato.

- Exploração: O grupo teatral e o dramaturgo exploram em detalhes, respectivamente, o problema em questão e o contexto organizacional em que se insere. Essa exploração requer ir além do nível de teorias consolidadas e familiarizar-se com as predominantes teorias em uso (Argyris, 1976). Assuntos típicos para a exploração, portanto, são não somente aspectos formais como estrutura organizacional ou relevância econômica do problema - importância marginal ou estratégica -, mas também aspectos como: interesses ocultos, regras implícitas, símbolos e seus significados, jargões, etc.

- Os métodos utilizados para a exploração dos tópicos são: observação participativa, entrevistas, incidentes críticos, análise de documentação, etc.

- Dramatização: A dramatização começa com a construção da trama. A trama é o recurso básico utilizado pelo dramaturgo para inserir a platéia na situação teatral e estimular sua curiosidade. Mais tarde, dependendo do método de trabalho, o texto dramático completo é escrito. Em muitos casos, a finalização do texto dramático é vista como uma tarefa contínua até o momento da encenação. Independentemente do estilo, espera-se que a peça reflita os resultados de observações e explorações realizadas.

- Mise-en-scène: Em uma etapa inicial, começa o processo de montagem da produção, envolvendo: distribuição de papéis, cenário, figurino, iluminação, ensaios, etc. $O$ diretor de palco é o personagem central nesse processo. Também inclui-se nessa execução a colaboração contínua da organização-cliente.
- Encenação: A encenação, feita por atores profissionais, geralmente ocorre em locais específicos na organização, como no hall de entrada ou em uma fábrica. Algumas vezes, a encenação é parte de uma conferência ou reunião anual - nesses casos, os atores encenam a peça em hotéis, centros de convenções ou teatros.

- Acompanhamento: Diferentemente de encenações de teatro clássico, o teatro organizacional é parte de um processo central de resolução de problemas. Dessa forma, o processo de produção também deve incluir atividades adequadas de acompanhamento: workshops, discussões em grupo para discutir o problema em questão, reflexões sobre alternativas, etc. Em muitos casos, facilitadores profissionais (e não os atores) são contratados para instituir e orientar esses processos de acompanhamento.

O modo de se fazer a produção depende do estilo do grupo teatral, do problema em questão e/ou da abordagem do dramaturgo. O leque de variação dos estilos de realização utilizados no teatro organizacional é bastante amplo: realista, naturalista, melodramático, absurdo, burlesco, etc., assim como variam as maneiras de dramatizar o problema: de forma concreta ou abstrata, em comédia ou em drama.

Independentemente da forma, em todos os casos o teatro organizacional objetiva envolver profundamente a platéia na situação-problema e confrontá-la com os conflitos ocultos, padrões de comportamento inconscientes ou com verdades dolorosas. A platéia é exposta a uma experiência incomum, vendo problemas bem conhecidos de seu ambiente de trabalho sendo encenados no palco por estranhos em um cenário jamais visto. Como resultado, a atmosfera durante as encenações é normalmente tensa. Há um silêncio desconfortável, risos e lágrimas. Na maioria das vezes, as reações a experiências específicas são muito fortes, até mesmo fisicamente, de forma que com freqüência as pessoas ficam banhadas de suor.

Figura 1 - Atividades do processo de produção

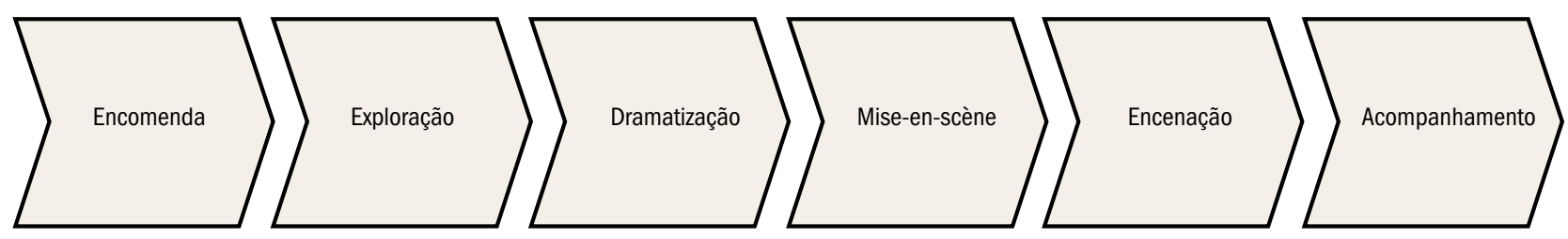


Essas reações já indicam que o teatro organizacional é potencialmente um meio poderoso para colocar as coisas em movimento. Esse modo teatral pode conscientizar as pessoas de conflitos que foram bloqueados por muito tempo, pode liberar situações paralisadas ou abrir à discussão o que normalmente é tido como indiscutível (Schreyögg, 1998). Em outras palavras, a dinâmica do teatro organizacional pode fazer desencadear movimento ou, usando os termos de Lewin (1943), pode descongelar situações bloqueadas.

Quais são os processos que causam esses efeitos do teatro organizacional e como podemos explicá-los? A seção a seguir é devotada a explorar essa dinâmica inerente em mais detalhes.

\section{EFEITOS DE MUDANÇA DO TEATRO ORGANIZACIONAL: EXPLICAÇÕES TEÓRICAS}

Perguntas sobre os fins e os efeitos do teatro organizacional são, em sua maioria, feitas a partir de um ponto de vista causal. Nessa visão, a encenação teatral é considerada um estímulo que deveria trazer uma resposta previsível, isto é, uma resposta da platéia em termos de mudanças de atitudes intencionais ou mesmo de novos padrões de comportamento. Em conseqüência, a qualidade do teatro organizacional corresponderia a uma função à medida que os efeitos pretendidos são atingidos. A "construção do estímulo" iria tornar-se o principal fator de sucesso. Entretanto, essa é uma perspectiva muito simplista. A idéia mecanicista de estímulo e resposta predeterminada não é compatível à natureza complexa do teatro organizacional.

A lógica do estímulo-resposta interpreta o estímulo - em nosso caso, a performance - como uma causa que necessariamente resulta em um efeito predeterminado. As mais recentes discussões em estética, teoria (cognitiva) da liderança ou artes performáticas (Strati, 1999; Meindl, 1995; Fischer-Lichte, 1997) criaram um desafio radical a essa lógica. Tornou-se claro que não podemos conceber esses complexos relacionamentos interativos de forma simplesmente unidirecional. O teatro produz significantes, usa atores, objetos pertencentes ao ambiente e outros signos para criar um sentido que deve ser percebido e interpretado pela platéia. Para entendermos os efeitos do teatro, devemos incluir conceitualmente a perspectiva da platéia. Qualquer mudança, se ocorrer, deve, antes de mais nada, ocorrer nas mentes da platéia, e, portanto, devemos explicar o efei- to do teatro organizacional da perspectiva da platéia. Por implicação, a questão fundamental não é mais como construir o estímulo, mas sim como a platéia lida com o confronto e a provocação que a encenação teatral lhe traz. Para lançar mais luz a essas questões, parece-me promissor fazer uso da teoria avançada de sistemas e, em particular, da teoria da observação de segunda ordem (Luhmann, 1997, 1998). O centro dessa teoria é o processo de percepção - como os diferentes observadores interpretam a realidade - que nos proporcionará a base para a reflexão sobre o processo básico de observação e suas implicações para as encenações do teatro organizacional.

\section{A observação da observação}

Começaremos pela encenação teatral. A platéia - departamento, divisão, etc. - vivencia a encenação; os membros da organização assistem à peça que dramatiza sequências de sua própria realidade, como problemas ou relacionamentos que são parte de seu trabalho do dia-a-dia: conflitos com o departamento ao lado, controvérsias com subsidiárias estrangeiras, discriminação implícita de mulheres, etc. Ao fazê-lo, primeiramente a platéia não observa os atores encenando uma peça (boa ou ruim), mas observam os resultados das observações que outros fizeram de sua organização, isto é, as observações do dramaturgo, do diretor, do produtor e/ou dos atores. Os membros da platéia assistem a suas rotinas diárias de trabalho, seus conflitos interdepartamentais, suas convenções, etc. sendo representadas no palco por atores e sua visão da realidade observada. Essas observações do grupo teatral, comunicadas pela peça no palco, confrontam os membros da platéia - o observador dessas observações - com uma nova visão que, muito provavelmente, difere muito de sua percepção usual da realidade. Conseqüentemente, o teatro organizacional pode causar uma experiência de ruptura, dividindo a realidade em dois níveis, a visão de realidade usual e familiar e a realidade teatral, isto é, a realidade encenada no palco.

Essa ruptura, ou duplicação, da realidade (Luhmann, 1997) é postulada neste artigo como sendo o processo fundamental para o entendimento dos efeitos de mudança que podem resultar do teatro organizacional. A duplicação da realidade é o ato de montar uma plataforma que permite a observação da visão da realidade bem conhecida, tomada como certa, de um ponto de vista distante, um ângulo que usa elementos conhecidos e símbolos da rotina de trabalho diária em uma nova combinação e um novo contexto. A duplicação, assim, colo- 
ca a visão conhecida em perspectiva e, ao mesmo tempo, a torna reflexiva, permitindo que a platéia veja simultaneamente duas realidades diferentes. No reconhecimento da discrepância entre essas realidades, a duplicação desencadeia um processo de reflexão: "Por que fazemos o que fazemos do modo como fazemos?". Isso também significa que o caráter construtivo das visões de realidade torna-se aparente.

Além disso, a observação da própria realidade pelos olhos dos atores - "observação de segunda ordem" pode fazer com que algo muito especial ocorra: a visão da realidade, antes tomada como certa, torna-se uma visão contingente. A experiência da divisão da realidade em duas realidades diferentes pela observação das observações dá à construção prévia da realidade um caráter contingente, tornando evidente que ela poderia ser diferente, levando à conclusão de que visões alternativas e mudanças são possíveis, pelo menos em princípio. As aparentemente inevitáveis construção e explicação de uma situação-problema livram-se de sua inevitabilidade. A duplicação teatral da realidade traz certa alienação do modo de pensar antes comum: ela impõe desordem. Ao vivenciar uma segunda construção de realidade, a construção anterior - normalmente tomada como certa - torna-se instável e, em conseqüência, aberta a mudanças.

Em resumo, o teatro organizacional confronta a platéia com uma perspectiva diferente de sua conhecida construção dos problemas e estimula uma análise mais detalhada dos padrões de comportamento habituais, construções perceptivas estabelecidas ou possíveis visões prejudiciais. Essa é a valiosa contribuição que o teatro organizacional pode dar no sentido da mudança. Qualquer mudança organizacional requer procedimentos que podem ampliar o escopo para além dos caminhos conhecidos.

Essa análise revela o papel e a relevância potenciais que o teatro organizacional pode ter em processos de mudança organizacional. O efeito de duplicação pode dissolver antigas inflexibilidades fazendo, dessa forma, com que as coisas movimentem-se.

Existem outras abordagens que visam a atingir efeitos de duplicação similares pelo desencadeamento de uma segunda observação - benchmarking, análises organizacionais ou consultoria de processos, mencionando somente algumas. Mas existe alguma vantagem comparativa que favoreça o meio do teatro organizacional?

Comparativamente, somente o teatro organizacional tem o potencial de fazer com que a observação de se- gunda ordem realmente aconteça. A forma teatral é a única a estimular o interesse das pessoas em uma duplicação de sua própria realidade e fazer com que se envolvam emocionalmente ao longo de todo o processo. O teatro organizacional não é uma árida reflexão crítica sobre a maneira usual de pensar ou um exercício didático de aprendizagem mas é algo diferente, que leva a rir, gargalhar, protestar, entristecer-se e/ou se alegrar.

O processo de duplicação, entretanto, não é tão direto como pode parecer. Como foi mencionado acima, ele não funciona como uma "máquina trivial" (Foerster, 1984). A experiência da observação de segunda ordem não produz resultados previsíveis patentes. O processo certamente faz as coisas se movimentarem, mas não há como programar com precisão o processo como um todo, incluindo os caminhos que as pessoas escolherão tomar no futuro. Os espectadores devem descobrir seu próprio caminho no sentido de se conciliar com a ruptura de sua construção dos problemas. Eles trabalham ao longo desse processo com base em seu próprio mundo cognitivo e seus mecanismos de construção de sentido (Weick, 1995), que estão, como se sabe, em constante mudança. Além disso, visões de mundo (weltanschauungen) são inerentemente complexas, e um estímulo como uma encenação de teatro organizacional pode sempre provocar novas e surpreendentes recombinações de sinais e significados.

\section{IMPLICAÇÕES PRÁTICAS}

Primeiramente, deve ser enfatizado que o teatro organizacional pode desencadear movimento, mas não é um programa de mudanças por si só. Ele pode ser um elemento em uma abordagem de mudança organizacional, mas não é um substituto para o gerenciamento de mudanças. Essa seria uma perspectiva fácil demais: simplesmente assista a uma peça de teatro organizacional e a mudança desejada realiza-se. Uma encenação teatral pode produzir contingência, estimulando a reflexão de rotinas e padrões tácitos na definição da situação-problema em jogo, aumentando a conscientização de que os problemas podem ser definidos de outra forma e de que há alternativas disponíveis para lidar com os problemas, mas não se deve ignorar o fato de que se trata somente de uma única intervenção, sem nenhum poder mágico de transformação.

Se a organização não tiver uma idéia de como lidar com a irritação teatral - a duplicação da realidade - para 
transformar a energia evocada em transformação organizacional, o processo pode falhar e a encenação teatral pode tornar-se um evento isolado sem nenhum efeito duradouro. Além disso, a encenação pode ainda causar danos ao expor as pessoas de forma emotiva a pontos críticos sem a promoção de uma maior reflexão. Dessa forma, é necessário discutir as experiências para integrar a duplicação em uma abordagem central de mudança. Isso enfatiza a importância de atividades de acompanhamento apropriadas, como foi resumidamente esboçado anteriormente.

De forma mais geral, remetendo-nos à Introdução e ao teatro de interpretação de papéis encenado na Polis Grega, o teatro organizacional parece ser mais eficaz ao proporcionar modelos para continuamente refletir problemas, conflitos e novos desafios organizacionais. De forma ideal, o teatro organizacional deve, dessa forma, fazer parte de uma abordagem integrada a uma organização em constante mudança, na qual a mudança deve ser uma característica comum da rotina de trabalho (Brown e Eisenhardt, 1997; Schreyögg e Noss, 2000).

\section{CONCLUSÃO}

Este artigo reflete uma tentativa de utilizar o teatro para lidar de forma mais otimizada com conflitos e inflexibilidades organizacionais. O teatro organizacional foi definido como peças teatrais customizadas encenadas por profissionais para uma dada organização ou subsistema. Neste artigo, uma estrutura conceitual foi oferecida, relacionando sistematicamente teatro organizacional e mudança organizacional. Especificamente, foi apontado o modo com que a dinâmica do teatro organizacional funciona como impulsionadora de processos de mudança. A principal força impulsionadora é concebida como a "experiência de ruptura"; a platéia é confrontada com diferentes construções da realidade, fazendo com que construções aparentemente inevitáveis tornem-se construções contingentes - nem necessárias, nem impossíveis.

A análise também revelou que o teatro organizacional não pode ser confundido com um programa de mudança por si só, e que as reações da platéia, por sua própria natureza, não podem ser programadas. A principal contribuição do teatro organizacional é fornecer um impulso para dissolver inflexibilidades.

Há ainda muito a ser feito. Pesquisas empíricas específicas fazem-se necessárias para examinar mais detalhadamente o contexto que permite a aplicação bem sucedida do teatro organizacional.

\section{Texto traduzido por Cristina Yamagami. Artigo convidado. Aprovado em 02/07/2002.}

\section{Nota}

Uma versão anterior deste trabalho foi apresentada na 60th Annual Conference of the Academy of Management, Washington D.C. 2001. O autor agradece pelas proveitosas sugestões e comentários de Heather Höpfl e Pierre Guillet de Monthoux.

\section{Referências bibliográficas}

ARAGOU-DOURNON, B. Unternehmenstheater in Frankreich: ein Überblick Über Eine Junge Erfolgsgeschichte. In: SCHREYÖGG, G.; DABITZ, R. (Eds.). Unternehmenstheater: Formen - Erfahrungen Erfolgreicher Einsatz. Wiesbaden : Gabler, 1999.

ARGYRIS, C. Single-loop and double-loop models in research on decision making. Administrative Science Quarterly, n. 21, p. 363-75, 1976.

BECKERMAN, B. Theatrical presentation: performer, audience and act. New York / London : Routledge, 1990.

BRESSER, R. Porsche: Die Strategische Entscheidung in den 90er Jahren. Diskussionsbeiträge des Instituts für Management, n. 3, 1995.

BRESSER, R. Winning strategies in a deconstruction world: some theoretical implications. Diskussionsbeiträge des Instituts für Management, n. 11, 1999.

BRESSER, R.; DUNBAR, R. Cinderella und ihr Reicher Onkel. Diskussionsbeiträge des Instituts für Management, n. 1, 1995.

BRESSER, R.; ESCHEN, E.; MILLONIG, K. Cyberbanking's business models: assessments from Germany. Diskussionsbeiträge des Instituts für Management, n. 12, 2000.

BROWN, S. L.; EISENHARDT, K. M. The art of continuous change: linking complexity theory and time-paced evolution in relentlessly shifting organizations. Administrative Science Quarterly, n. 42, p. 1-34, 1997.

ESCHEN, E. Mittelstandsholding: Holdingstrukturen für Kleine und Mittelgroße Unternehmungen. Diskussionsbeiträge des Instituts für Management, n. 7, 1998.

FISCHER-LICHTE, E. Die Entdeckung des Zuschauers. Tübingen / Basel : Francke, 1997.

FOERSTER, H. V. Principles of self-organization: in a socio-managerial context. In: ULRICH, H.; PROBST, G. J. B. (Eds.). Self-organization and management of social systems. Heidelberg / Nova York : Springer, 1984. p. 2-24. 
GRIEB, C. Branchenkultur versus Unternehmenskultur. Diskussionsbeiträge des Instituts für Management, n. 6, 1997.

LEPLÂTRE, F. (Ed.) La formation se met en scène. Paris : s.n., 1996.

LEWIN, K. Forces behind food habits and methods of change. Bulletin of the National Research Council, n. 108, p. 35-65, 1943.

LUHMANN, N. Die Kunst der Gesellschaft. Frankfurt : Suhrkamp, 1997.

LUHMANN, N. Observations on modernity. Stanford : Stanford University Press, 1998.

MEINDL, J. R. The romance of leadership as a follower-centric theory: a social-constructionist approach. Leadership Quarterly, n. 6, p. 329-41, 1995.

MEISIEK, S.; DABITZ, R. Unternehmenstheater und Wandel: die Rolle der Katharsis. Diskussionsbeiträge des Instituts für Management, n. 9, 1998.

PETZOLD, H. Situationsanalyse und intensiviertes Rollenspiel in der Industrie. In: DERS (Ed.). Angewandtes Psychodrama in Therapie, Pädagogik, Theater und Wirtschaft. Paderborn : Junferman, 1972. p. $358-72$

POISSONNEAU, C. Théâtre á la carte: l'entreprise mise en scène. Actualité de la Formation Permanente, n. 120, p. 68-70, 1992.

ROSEN, M. You asked for it: Christmas at the bosses expense. Journal of Management Studies, n. 25, p. 462-80, 1988.

SCHREYÖGG, G. Unternehmenstheater als Intervention. Organisationsentwicklung, v. 18, n. 1, p. 52-9, 1998.

SCHREYÖGG, G. Definition und Typen des Bedarfsorientierten Theatereinsatzes in Unternehmen. In: SCHREYÖGG, G.; DABITZ, R. (Eds.). Unternehmenstheater: Formen - Erfahrungen - Erfolgreicher Einsatz. Wiesbaden : Gabler, 1999.
SCHREYÖGG, G. DABITZ, R. Unternehmenskultur Analysieren Lernen: Bericht Über den Einsatz von Spielfilmen in der Seminararbeit. Diskussionsbeiträge des Instituts für Management, n. 4, 1996.

SCHREYÖGG, G.; DABITZ, R. (Eds.). Unternehmenstheater: Formen Erfahrungen - Erfolgreicher Einsatz. Wiesbaden : Gabler, 1999.

SCHREYÖGG, G.; NOSS, C. Reframing change in organizations: beyond the equilibrium model. Diskussionsbeiträge des Instituts für Management, n. 8, 1998.

SCHREYÖGG, G.; NOSS, C. Reframing change in organizations: the equilibrium logic and beyond. In: 59TH ANNUAL MEETING, 2000, Toronto. Academy of Management: Best Paper Proceedings.

STRATI, A. Organization and aesthetics. Thousand Oaks : Sage, 1999.

WEHNER, H.; DABITZ, R. Bedarfsorientierter Theatereinsatz in Unternehmen: Eine Bestandsaufnahme des Deutschen Marktes. Diskussionsbeiträge des Instituts für Management, n. 10, 1998.

WEHNER, H.; DABITZ, R. Bedarfsorientiertes Theater in Deutschland: Eine empirische Bestandsaufnahme. In: SCHREYÖGG, G.; DABITZ, R. (Eds.). Unternehmenstheater: Formen - Erfahrungen - Erfolgreicher Einsatz. Wiesbaden : Gabler, 1999.

WEICK, K. E. Sensemaking in organizations. Thousand Oaks : Sage, 1995.

ZAJAC, E.; KRAATZ, M.; BRESSER, R. Toward a normative theory of organizational change and performance. Diskussionsbeiträge des Instituts für Management, n. 2, 1995.

ZAJAC, E.; KRAATZ, M.; BRESSER, R. Modeling the dynamics of strategic fit: how organizational resources and environmental forces affect the desirability of strategic change. Diskussionsbeiträge des Instituts für Management, n. 5, 1997. 